\title{
Planes urbanos y disputas locales alrededor de los predios ferroviarios: la historia de Bahía Blanca, entre grandes anhelos y modestas actuaciones
}

María Alejandra Saus

Doctora en Arquitectura (UNR), especializada en funciones y efectos urbanísticos de los ferrocarriles en los campos de la geografía, la historia urbana, el urbanismo, la arquitectura y la ingeniería del transporte (IHUCSO, UNL - CONICET).

produccioncientificaydocencia@gmail.com

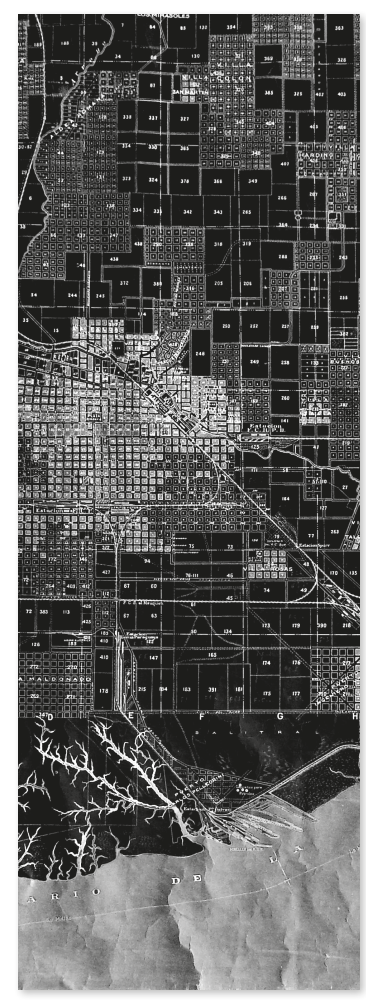


Planes urbanos y disputas locales alrededor de los predios ferroviarios: la historia de Bahía Blanca, entre grandes anhelos y modestas actuaciones

\section{Resumen}

Durante el siglo XX Bahía Blanca fue un caso peculiar en la reestructuración ferroviaria argentina. Si bien la ciudad había sido un importante núcleo ferroportuario, la racionalización de infraestructuras - a cargo del Ministerio de Transporte e iniciada en 1948- estuvo concentrada en otras ciudades del país. Por ello, en la historia urbana y urbanística de Bahía Blanca la sensación de un desarrollo incompleto contrasta con grandes aspiraciones inalcanzadas. El objetivo del artículo es comparar imaginarios y realidades en torno a los predios ferroviarios desafectados, analizando documentos de la prensa y de los planes urbanos. Dicha tarea ha sido concebida en referencia a la historia del urbanismo en la Argentina y a sus paradigmas disciplinares.

\section{Palabras clave}

Bahía Blanca; infraestructura ferroviaria; imaginarios urbanos; historia del urbanismo.

\section{Urban plans and local disputes around the railway lands: the history of Bahia Blanca, between great desires and poor actions}

\begin{abstract}
During the Twentieth Century Bahía Blanca City was a peculiar case in the Argentinian railway restructuring process. Although the city had been an important railway and port centre, the rationalization of the infrastructures -in charge of the Ministry of Transport and initiated in 1948- was concentrated in other argentine cities. For that reason, in the urban history and the urban planning history of Bahía Blanca, the feeling of an incomplete development contrasts with great desires unreached. The objective of this article is to compare urban imaginaries and concrete realities around de railway lands, by analysing press and urban plans documents. The task has been done regarding the history of urban planning in Argentina and its disciplinary paradigms.
\end{abstract}

\section{Keywords}

Bahía Blanca City; railway infrastructure; urban imaginaries; urban planning history.

\section{Planos urbanos e disputas locais em torno dos prédios ferroviários: a história de Bahía Blanca, entre grandes desejos e ações modestas}

\section{Resumo}

Durante o século XX, Bahía Blanca foi um caso peculiar na reestruturação ferroviária argentina. Embora a cidade tenha sido um importante núcleo ferroviário, a racionalização da infraestrutura - pelo Ministério do Transportes e iniciada em 1948 - esteve concentrada em outras cidades do país. Portanto, na história urbana e no planejamento urbano de Bahía Blanca, o sentimento de desenvolvimento incompleto contrasta com grandes aspirações não alcançadas. O objetivo do artigo é comparar imaginários e realidades em torno das instalações ferroviárias desafeiçoadas, analisando documentos da imprensa e planos urbanos. Essa tarefa foi concebida com referência à história do planejamento urbano na Argentina e seus paradigmas disciplinares.

\section{Palavras chave}

Bahía Blanca; infraestrutura ferroviária; imaginários urbanos; história do urbanismo. 


\section{Introducción}

Bahía Blanca, como tantas otras ciudades argentinas, acompañó sus procesos urbanos y sus prácticas urbanísticas simbolizando aquello que "aspiraba ser”, según discursos hegemónicos urdidos entre lo real y lo imaginario. En esa trama es dable sugerir un análisis que, partiendo de la grandilocuencia de ciertas proposiciones referidas al hecho urbano, arribe a las exiguas concreciones que le sucedieron en la práctica. Una sucinta revisión podría comenzar con el origen del poblado: la fundación de la Fortaleza Protectora Argentina (1828),

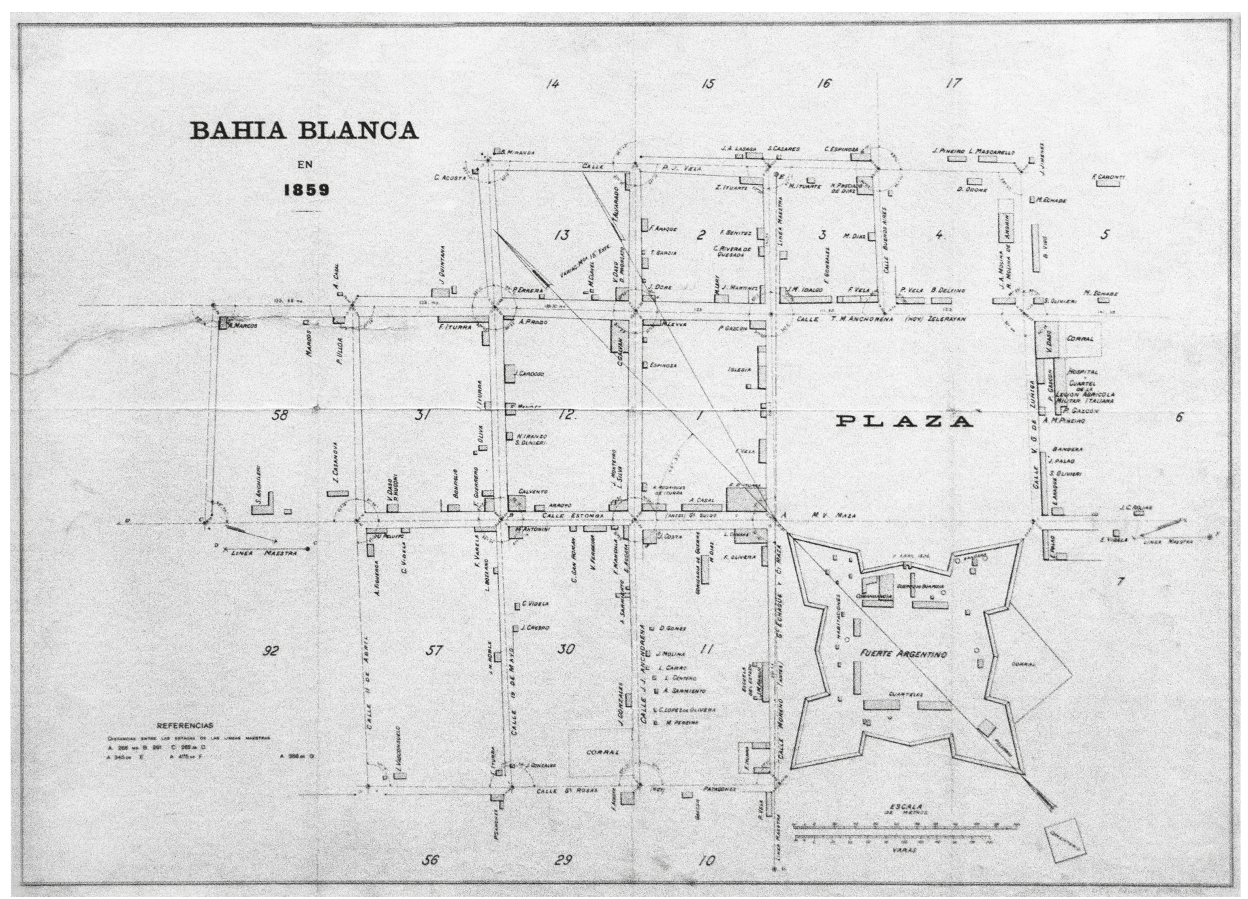

Figura 1. Fuerte Argentino, asiento originario. Fuente: Mapoteca de la Biblioteca Rivadavia. Signatura topográfica 158 (escala gráfica en metros y varas) 
1. En el período 1904-1924, este fue gestionado por el Ferrocarril Buenos Aires al Pacífico (FCBAP), para ser finalmente transferido a la empresa FCS. ese fuerte que, en rigor, era bastante débil porque estaba construido en barro y tendía a desmoronarse (figura 1). Tal apelativo — que habría estado más próximo a su deseo- ejemplifica retóricas que circularon también cuando el capital ferro-portuario provocaba una explosión urbanística hacia finales del siglo XIX. Por entonces, imaginarios de una cultura letrada ensayaron analogías optimistas del progreso urbano: Bahía Blanca era la "California del Sur", la "Liverpool Argentina", la "New York de Sudamérica" (Ribas, 2007), entre otras imágenes que el cronista Benigno Lugones sintetizó como "britanización” debido al origen del capital (LugonEs, 1883, pág. 1).

A causa de la injerencia británica en la construcción de infraestructura ferro-portuaria y del acoplamiento de la elite local a la lógica extrovertida implicada en ese dominio, la ciudad cobró protagonismo nacional y llegó a tener cinco terminales portuarias. Señaladas de este a oeste en la figura 2, estas son: Belgrano y Rosales en Punta Alta, Ing. White, Galván y Cuatreros. La primera fue la base naval más importante del país (1898). La siguiente estaba administrada por el Ferrocarril Rosario a Puerto Belgrano (FCRPB), de propiedad francesa, con su estación abierta en 1922 al sureste del área central. La tercera estaba concesionada por el Ferrocarril del Sud (FCS), de capital británico, y la estación inaugurada en 1884 al centro-este de la planta urbana. La cuarta pertenecía al Ferrocarril Bahía Blanca al Noroeste (FCBBNO), también británico, cuyo edificio de viajeros data de 1891 y fue ubicado al sur de la cuadrícula ${ }^{1}$, y, finalmente, el muelle de Cuatreros pertenecía al frigorífico Sansinena (GueRREIRO, 2011). La localización urbana de las estaciones ferroviarias puede verse representada en la figura 3.

Tan promisorio era el futuro de esa urbe ferro-portuaria que se llegó a imaginar que no necesitaría gobierno externo para conducir sus destinos, conjeturando una gestión autónoma e independiente. No obstante, su distancia con la recientemente creada Capital Federal (1880) y las aspiraciones presidenciales del gobernador Dardo Rocha truncaron sus aspiraciones de convertirse en capital provincial cuando en 1882 se concretó la sede en La Plata. Como respuesta, en 1884 el diario local El Porvenir propuso que Bahía Blanca fuera convertida en la capital de una nueva provincia, a partir del proyecto de dividir en dos partes el territorio bonaerense. En 1898 el diario La Nueva Provincia insistió en esa solicitud, que quedaría plasmada solo en su nombre. Diputados nacionales, gobernadores y particulares sostuvieron la idea que Domingo Pronsato retomaría, sin éxito, en 1943 (Cernadas de Bulnes, 1996).

Cuaderno Urbano. Espacio, Cultura, Sociedad - Vol. 27 - N. ${ }^{\circ} 27$ (Diciembre de 2019) - Pp. 167-188 - ISSN1666-6186 
Planes urbanos y disputas locales alrededor de los predios ferroviarios:

la historia de Bahía Blanca, entre grandes anhelos y modestas actuaciones

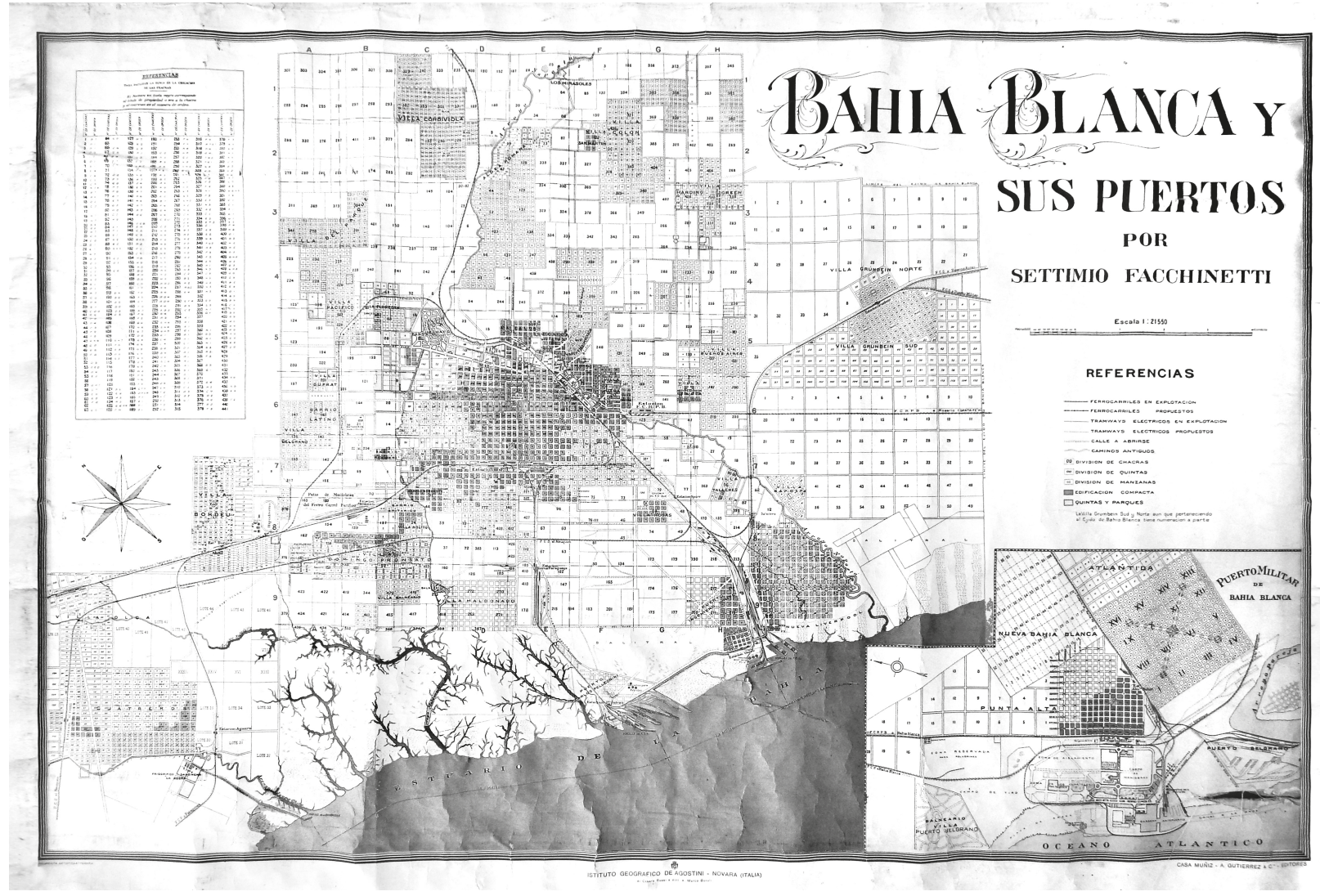

Una vez expandida y densificada la trama urbana, con las pulsiones propias del capital global y de las políticas nacionales de inmigración, y tras haberse construido las infraestructuras que harían de Bahía Blanca un gran nudo ferro-portuario, la opinión pública local comenzaría a discutir otros asuntos, volviendo a vincular grandes anhelos y pequeñas prácticas de una forma dilatada hacia los primeros. En ese momento entraba en la escena
Figura 2. Bahía Blanca y sus puertos. Fuente: Archivo Histórico Municipal de Bahía Blanca. Inventario 15 (Esc. 1:21.550) 


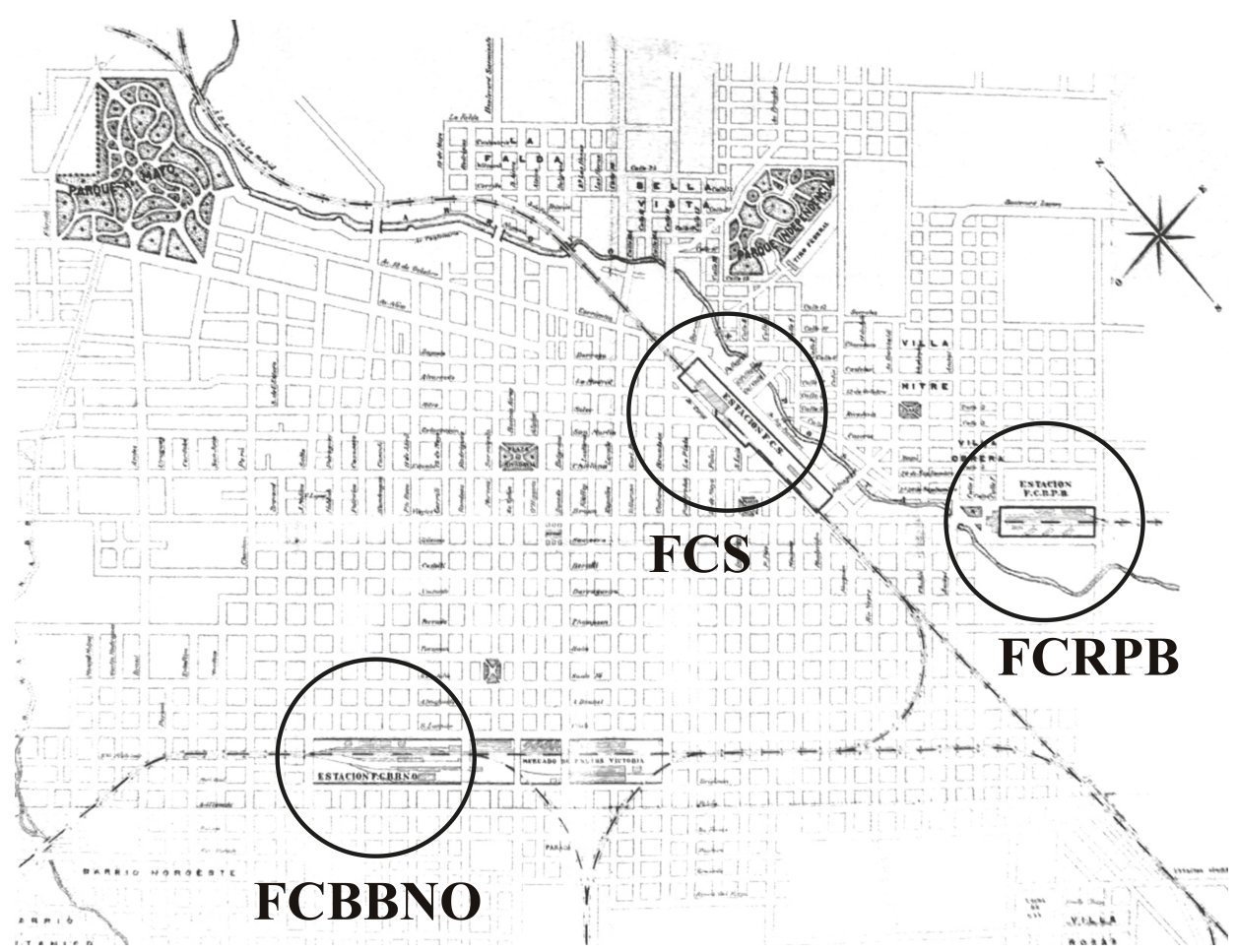

Figura 3. Localización de las estaciones ferroviarias. Fuente: elaboración propia a partir de plano del Archivo del Museo Taller Ferrowhite (sin escala, ni fecha)

nacional una primigenia versión del Urbanismo, esa disciplina cuyo discurso técnico fue rápidamente apropiado en la Argentina. Rigotri (2014) sostiene que tal afiliación implicó construir frases propias con vocabulario y sintaxis recibidos, a la manera de "invenciones" —en palabras de MicheL DE CERTEAU — como una reapropiación en el consumo mediada por singularidades locales, políticas públicas cíclicas e internas profesionales. 
Bahía Blanca comenzó a ser objeto de especulaciones urbanísticas cuando la infraestructura ferroviaria empezaba a ser un gran obstáculo, ya que, al fragmentar la continuidad del tráfico urbano, se volvía incompatible con el transporte automotor que traía ráfagas de una modernidad alternativa que los urbanistas blandieron al instante. Por entonces circunstancias históricas, el difícil panorama económico y un clima de hostilidad respecto del universo ferroviario desembocaron en políticas públicas proteccionistas que incluyeron la nacionalización de los ferrocarriles finalizada en 1948 (López, 2008). Así empezó un proceso de racionalización de su infraestructura, con implicancias sobre las estructuras urbanas de las ciudades argentinas. Para los urbanistas, los predios ferroviarios vacantes constituyeron un espacio para la utopía que inspira la tabula rasa, ese comienzo desde cero que tanto seduce a arquitectos y urbanistas, un salto al vacío casi siempre destinado a quedar en el papel.

En ese momento el transporte vehicular cobraba protagonismo en discursos técnicos, políticos y parroquianos que lo posicionaban como vía de escape a la hegemonía británica que Bahía Blanca mostraba con elocuencia. Así, desafectadas algunas de las estaciones ferroviarias, empezaría a especularse con su uso para otros destinos como terminales de autobuses. Por su parte, los pasillos ferroviarios pretendían ser aprovechados como avenidas de penetración al centro, y los terrenos vacantes utilizados para construir viviendas. Empero, tales alternativas serían motivo de disputas locales, definición de prioridades, del hallazgo de nichos profesionales, de convenios entre escalas estatales, solicitudes vecinales, grandes propuestas y exiguas concreciones.

En suma, el objetivo del artículo es exponer esa trama de ideas y acciones tejida en torno a los predios ferroviarios y a la racionalización de la infraestructura que a mediados del siglo XX parecía inminente. Asimismo, se afirma que el volumen de los imaginarios y discursos desplegados en Bahía Blanca ha superado la densidad de las prácticas urbanísticas en diversos momentos de su historia. Para argumentarlo, el artículo se ordena de forma cronológica y revisa los planes urbanos históricos de Bahía Blanca situando la infraestructura ferroviaria en el foco del análisis. La metodología recurre a la técnica del análisis documental para estudiar los planes desde sus fuentes primarias y apela a la prensa local para ponderar las discusiones y representaciones por estos creadas. 


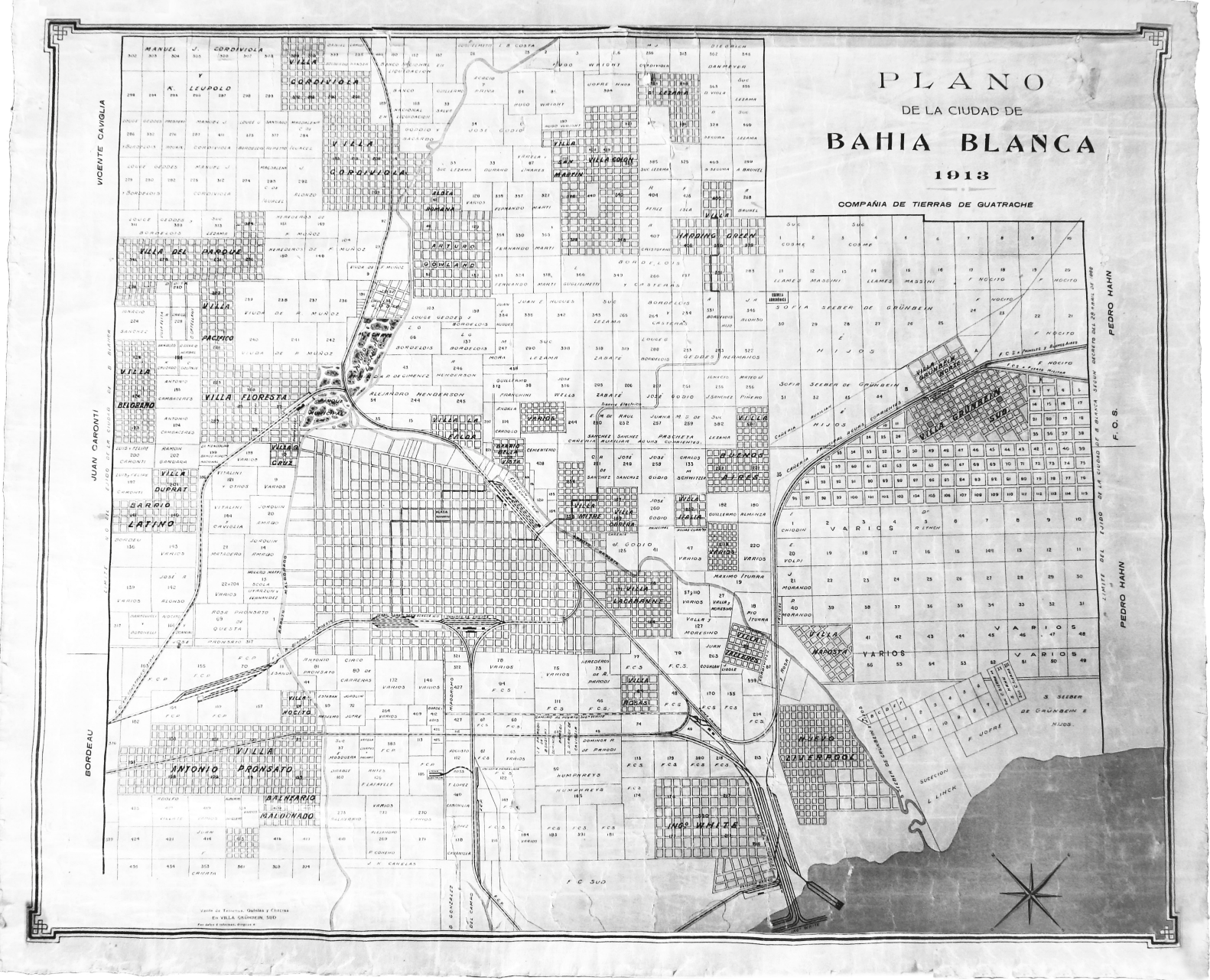

Figura 4. Urbanizaciones hacia 1913. Fuente: Archivo Histórico Municipal de Bahía Blanca (sin escala). Inventario 2 


\section{Las estaciones ferroviarias entre los anillos y diagonales del Plan Dujarric}

El primer plan urbano con registro oficial se remonta al año 1909 y fue encomendado durante el tercer mandato del intendente Jorge Moore. Este convocó al arquitecto francés Louis Faure-Dujarric para planificar la expansión urbana de Bahía Blanca. Dujarric se había formado en París, en L'Ecole des Beaux Arts, y proyectaría en la Argentina diversos edificios particulares y deportivos, como el Hipódromo Argentino de Palermo. En Bahía Blanca abordó la planta urbana de un modo que extendiera la urbanización de forma ordenada, a los fines de planificar desde el Estado local la subdivisión de tierras que estaban siendo apropiadas por el sector privado (figura 4). A partir de una serie de avenidas radiales arboladas y otras de circunvalación que enlazaban tres parques periféricos de 400, 129 y 56 hectáreas, el autor ideaba el ordenamiento de esa extensión urbana ligada al proceso de acumulación capitalista y traducida en renta urbana. Se afirma esto porque ya en 1883 Lugones lo alertaba: "repito que hoy, casi toda la tierra no edificada es de los ingleses, tanto en los costados de la vía como a orillas de la bahía y principalmente entre el pueblo y el puerto" (Lugones, 1883, pág. 1).

Dujarric apeló a una batería de recursos bastante comunes por entonces: avenidas diagonales (con la premisa de acelerar el tráfico y generar perspectivas pintorescas), bulevares de circunvalación (para evitar penetraciones al centro y crear gradaciones en las rentas del suelo), parques periféricos (para higienizar y contener la expansión) y, finalmente, forestación y conjuntos escultóricos monumentales (figura 5). Un antecedente inmediato de esas ideas había sido el Plan Bouvard para Buenos Aires (1907-1909), encomienda satisfecha a solicitud del intendente Carlos Alvear y destinada a efectuar las mejoras del Centenario. Sin embargo, Bouvard había hecho un reconocimiento de las preexistencias que no parecen haber sido tenidas en cuenta en la rígida composición de Dujarric. En principio, porque su rigurosa geometría fue pensada como un layer de diagonales y circunvalaciones que no procuraría ninguna intervención sobre el centro tradicional. Si bien las estaciones ferroviarias del FCS y del FCBBNO —así como sus enlaces a los puertos- están dibujadas en el plano, el proyecto de espacios públicos no hace referencia alguna a los edificios de pasajeros. En rigor, intervenir el área central era una forma de preservarla, valorizarla, frente a la especulación inmobiliaria que entrañaba la extensión indefinida de la planta urbana y, por ello, el recurso utilizado por Dujarric sería homologable a una práctica conservadora. 


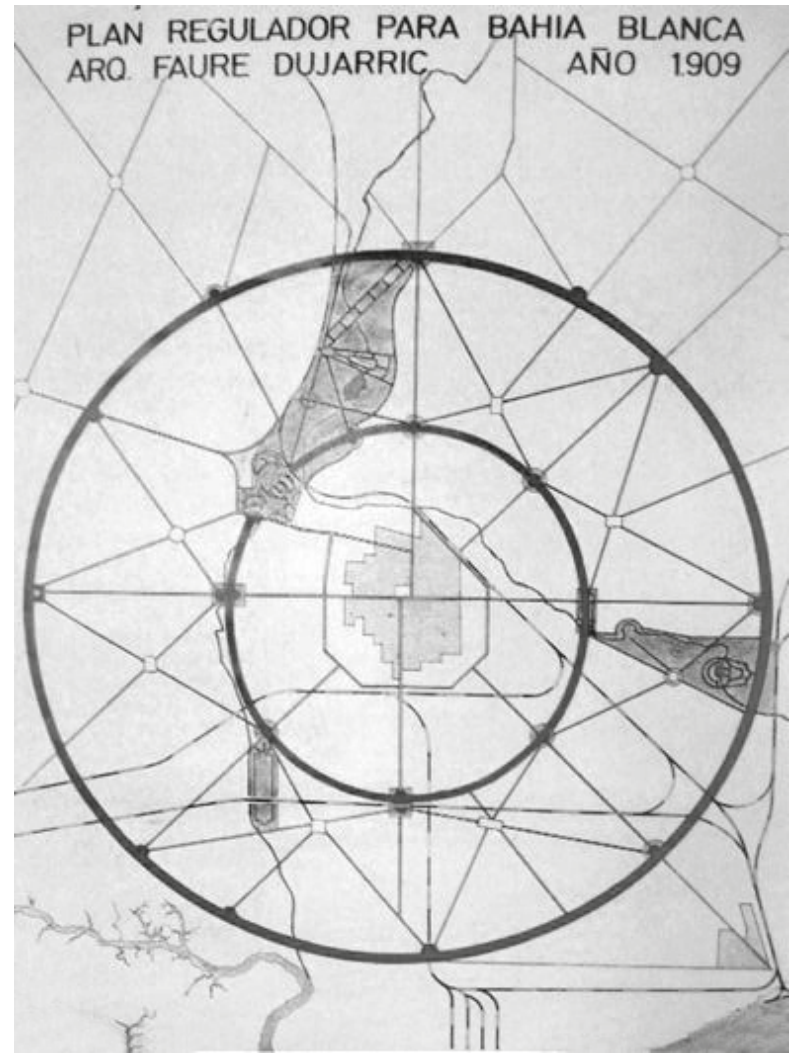

Figura 5.

Plan Dujarric

(1909). Fuente:

Municipalidad de

Bahía Blanca

La recepción del proyecto fue dispar en la gama de matices que ofreció la prensa local. El diario Bahía Blanca hizo una referencia peyorativa hacia "aquel fantástico plano” (BAHÍA BLANCA, 28/11/1909, pág. 1), criticando el planteo y la profesión de su autor, contrastando ese plan con las ideas de Bouvard que eran ponderadas por emanar de los saberes de un ingeniero, cuando, en realidad, Bouvard era arquitecto e incluso había sido cuestionado en Buenos Aires (Bahía Blanca, 11/09/1909, pág. 4). El proyecto fue calificado como un 
"delirio" que, inspirado en la obra de Haussmann para París, sembraba dudas también sobre sus aspectos financieros. Por su parte, El Censor calificó el diseño como "manía de grandezas" poniéndolo a tono con las exiguas posibilidades financieras del Municipio (El Censor, 24/11/1909, pág. 1). En las antípodas, La Nueva Provincia —diario afín con la ideología radical del intendente que hizo la encomienda- expresaba lo que sigue:

Hoy llega a Bahía Blanca el notable arquitecto M. Faure Dujarric... es el motivo que trae nuevamente al distinguido hombre de ciencia y de trabajo... para la realización de aquel laudable pensamiento de progreso... Bahía Blanca transfigurada por la virtud del arte arquitectónico y sus complementos científicos. Somos entusiastas de este gran impulso a la expansión armónica (La Nueva Provincia, 23/11/1909, pág. 2).

Esas las líneas permiten entrever que, a excepción de las opiniones vertidas por el diario oficialista, la prensa local valoró negativamente el plan por considerarlo al margen de los recursos materiales del Municipio. Por su parte, el discurso de Dujarric en la sesión extraordinaria del Concejo Deliberante reforzaba la idea de no intervenir el área central, y fue publicado en el diario La Nueva Provincia, como era de suponerse: "Quiero hablar de la celeridad de la circulación, de la necesidad absoluta de ir de un punto a otro en el menor tiempo posible"; de ese modo argumentaba a favor de sus calles diagonales y sus avenidas de circunvalación, sosteniendo que

un plano sobre papel, es un arreglo de las cosas existentes para el futuro... no tocar las casas, alejarse de los terrenos valiosos... respetar primero al centro tratándolo como el futuro corazón de la ciudad... ahora no podemos atrevernos a un cambio superior a los recursos actuales (LA Nueva Provincia, 25/11/1909, pág. 2).

De tal modo, en su alocución explicaba su intención de agilizar el tráfico, traducida en nuevas avenidas, su idea de un centro histórico y una periferia moderna, su austeridad y mesura, posiblemente ya al tanto de las críticas. Sin embargo, el plan no fue ejecutado, y quedaría como primer intento integral por sistematizar la expansión urbana.

\section{La infraestructura ferroviaria como espacio vacante para el proyecto moderno de Roca}

El pomposo plan quedó trunco mientras iba perfilándose otro paradigma urbanístico que a mediados del siglo $\mathrm{XX}$ abandonaba las diagonales y las perspectivas pintorescas para 
2. También fue autor del Plan Regulador de Santa Fe (1944).

3. Cuando Perón asumió su primer mandato el vencimiento de la "Ley Mitre" era una coyuntura favorable a la estatización de los ferrocarriles. En 1907 esa norma había dado prerrogativas por cuarenta años a las compañías ferroviarias a cambio de conservar el Estado la potestad de regular las tarifas. El contexto internacional era proclive al intervencionismo estatal en materia económica y el sector público empezó a normar los términos de un liberalismo cuestionado. Por entonces, Gran Bretaña tenía una deuda con la Argentina en concepto de exportaciones, la cual hizo posible el trueque que permitió adquirir los ferrocarriles en el año 1948 (Waddell, 2009).

4. El Plan Regulador de Bahía Blanca detectaba que las rutas nacionales $N^{\circ} 3,33$ y 35 atravesaban el ejido urbano superponiéndose tal sistema regional al otro local. Sostenía que más allá de la avenida de circunvalación prevista por Vialidad, debíanse proyectar autopistas sobre los antiguos trazados ferroviarios. Agregaba también una zonificación apropiada al nuevo Código de Edificación, entre otros aspectos que quedarían solo en intenciones. volverse una disciplina "científica". En sus representaciones apelaba a metáforas biológicas de una ciudad concebida como "organismo vivo", en la esfera del discurso "verídico" de especialistas diplomados que ofrecían sus servicios a los municipios. Uno de ellos era Miguel C. Roca, formado en el Instituto de Urbanismo de París y autor del Plan de Bahía Blanca (1950). ${ }^{2}$ Este plan incluía un expediente urbano estadístico y una propuesta técnica: el nuevo "sistema circulatorio", los "pulmones verdes", la estación única ferroviaria, los barrios jardín, un zonning con áreas para industrias y vivienda obrera imaginada sobre terrenos ferroviarios desafectados. El plan estuvo articulado a la presidencia de Juan D. Perón, quien creó un clima favorable a propuestas urbanístico-ferroviarias. ${ }^{3}$

Ese período de la historia política argentina se caracterizó por una tendencia a planificarlo todo, a intentar equilibrar aquello que el capital foráneo había distribuido en su propio beneficio y que ScALABRINI OrTiz (2006) denunciaba en la década del 30 como "colonialismo velado". Planificar con equidad significaba corregir el "embudo" ferroviario hacia los puertos, redistribuir las fábricas sobre el territorio nacional, redescubrir las sierras y el mar, construir viviendas para obreros. El marco estaba en el Plan de Gobierno del año 1946 (Primer Plan Quinquenal) y también en el Segundo Plan Quinquenal (1952) (Rigotri, 2014). Inéditamente este dispuso que las ciudades tuvieran planes reguladores para actualizar el catastro y revaluar propiedades en caso de expropiaciones.

En ese contexto histórico, Roca comenzó a elaborar la Remodelación Ferroviaria y Urbanística de la Ciudad de Bahía Blanca (1949), publicada en 1950 junto al Plan Regulador. Por entonces, el Estado nacional encaraba planes de racionalización ferroviaria desde el Ministerio de Transporte, ya que era preciso sistematizar las redes heredadas de numerosas compañías con ramales paralelos, múltiples estaciones, diferentes trochas, entre otros conflictos que recayeron en la órbita nacional. Tales medidas tuvieron efectos urbanísticos escasamente estudiados y, aunque motivaron respuestas especializadas, fueron algo ingratas para actores locales apenas influyentes en la práctica. ${ }^{4}$

El plan incluía el levantamiento de las tres estaciones ferroviarias (La Nueva Provincia, 23/6/1949). En el inmueble del ex FCS sugería ubicar una estación de autobuses, siendo esta la primera vez que una pieza técnica abordaba problemas ferroviarios y veía sobre sus huellas la solución al viejo dilema de los colectivos. Hasta entonces, el transporte vehicular de media y larga distancia operaba en locales propios de las empresas prestadoras. 


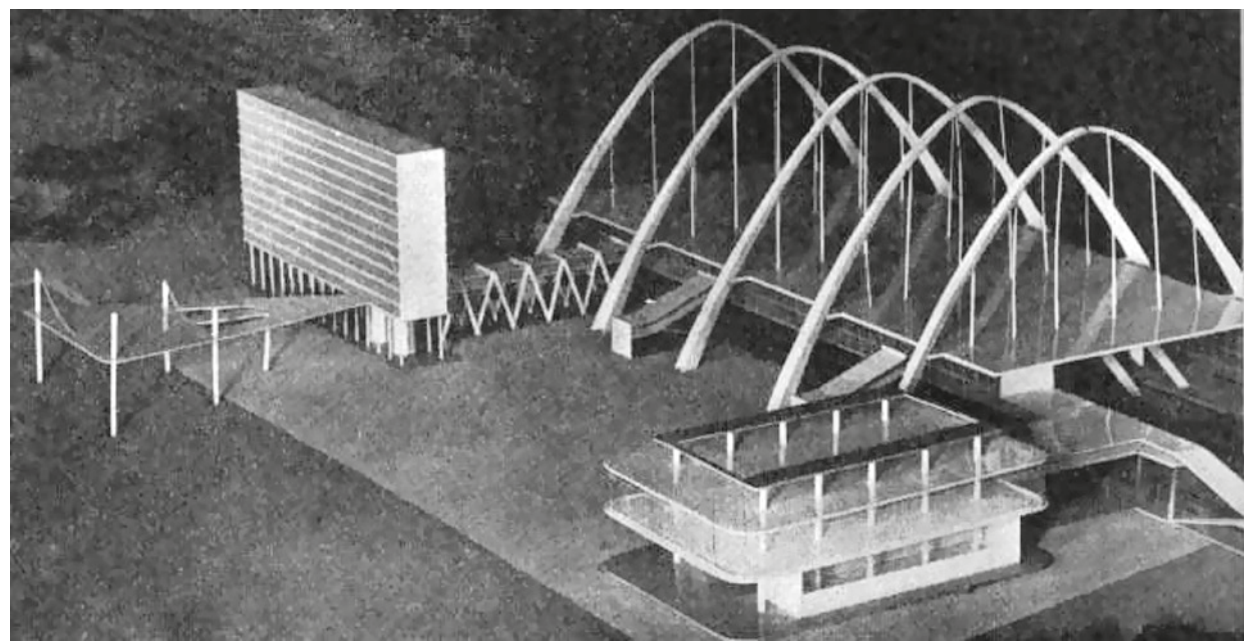

Figura 6. Planta de la unidad vecinal en terrenos del ex FCBBNO y maqueta de la estación ferroviaria. Fuente: RocA, M. C. (1950) pp. 328 y 325.

Asimismo, Roca propuso retirar la estación del ex Ferrocarril Rosario Puerto Belgrano FCRPB (1922), al sur de la anterior, y fuera de servicio desde 1949. Para la estación del ex FCBBNO estipulaba una demolición que no fue cuestionada (La Nueva Provincia, 14/2/1949), y en su lugar pretendía ubicar un barrio obrero de monoblocks — unidad vecinal para 800 familias-, un hotel ferroviario y un centro de esparcimiento. Al sur se construiría la nueva estación ferroviaria centralizadora junto al barrio industrial (figura 6) (RocA, 1950, pág. 320-328).

"Este es, a grandes rasgos, el proyecto trazado por el Ministerio de Trasportes [sic] que tanto interés ha despertado en la ciudad, como lo demuestra la gran cantidad de público que ha visitado el lugar de la exposición” (LA Nueva Provincia, 10/6/1949). Así quedaba valorado el proyecto en la prensa, y resulta evidente que el Municipio buscaba consenso exhibiéndolo al público para involucrar a sectores específicos: "Ha tenido amplia repercusión ayer en 
todos los círculos ligados a las actividades económicas, sociales, culturales y profesionales” (La Nueva Provincia, 28/5/1949). No obstante, discursos, convites y un concierto de piano en el teatro municipal serían los aspectos más notorios de un plan sin materialización (LA NuEva Provincia, 2/6/1949).

\section{La arquitectura ferroviaria para la regeneración barrial}

Ya sin remodelación ferroviaria en un horizonte cercano, pero ante la vacancia que la nacionalización había dejado en la estación del ex FCRPB, en 1952 el diario El Atlántico solicitó que el edificio de viajeros fuera destinado a albergar una terminal de ómnibus de media y larga distancia. El diario repudiaba las improvisadas paradas de colectivos, ejemplificando la posible solución con obras realizadas por el Ministerio de Transporte en Mar del Plata (El Atlántico, 18/3/1952). Importa el dato porque el reclamo en virtud de lo hecho en La Plata, Rosario, Córdoba o Mendoza se volvió una constante en la prensa bahiense, insinuando la desatención del Estado nacional. Asimismo, en 1958 la municipalidad había iniciado gestiones para la cesión del inmueble con el fin de usarlo como estación de trolebuses (La Nueva Provincia, 10/6/1958). Un mes después se planeaba que el edificio albergara el mercado de frutos, y así continuaron elucubrándose destinos que parecían ser más bien un pretexto para conseguir la transferencia.

En una nota de 1962 se exponían “los problemas de Bahía Blanca”, detallándolos para las distintas modalidades de transporte, haciendo una grandilocuente analogía:

Cuando el barco se acerca a Rio de Janeiro o a Buenos Aires, el mar de luces... y los masivos rascacielos... sellan, para siempre, la representación que la gente tiene de las mismas. ¿Qué se retiene en el caso de Bahía Blanca? Un empedrado miserable y un arroyito convertido en basural (La Nueva Provincia, 14/3/1962).

Si acordamos que la cultura anida en el lenguaje y lo abordamos como dato empírico (Schuster, 2002), el significado de la cita no vale por su realismo, sino por el hecho de evidenciar al sujeto que escribe y explicitar una representación urbana con ambiciones algo desmedidas. Desde ese lugar de sentido, los reclamos locales por la localización de la terminal de ómnibus en la estación Rosario prosiguieron: "Desde largo tiempo se proyecta una estación terminal de ómnibus en nuestra ciudad... Se piensa 
en la ex estación Rosario Puerto Belgrano, convertida ahora en lugar abandonado" (La Nueva Provincia, 26/12/1962). Para mitigar ese lastre "se intensifican los pasos para llevar adelante esa aspiración de la que se viene hablando en Bahía Blanca desde hace mucho tiempo", se exponía en una inspección ocular al inmueble del ex FCRPB (LA Nueva Provincia, 29/12/1962).

Pero las disputas por la transferencia de la estación de origen francés no eran solo un asunto entre Municipio y Nación. También habría discrepancias vinculadas con el porvenir de dos sectores urbanos que necesitaban cobrar nuevo impulso: el sureste junto al ex FCRPB y el suroeste (barrio Almafuerte), donde vecinos y comerciantes solicitaban la reapertura del ex FCBBno (La Nueva Provincia, 29/5/1962).

No solo para los usuarios esa necesidad se torna cada día más imperiosa, sino que también para el sector de la estación precitada importaría un innegable beneficio en el aspecto comercial y de movimiento general, dando más vida a la actividad de un populoso barrio (LA Nueva Provincia, 8/10/1964).

Por su parte, en 1965 el diputado provincial Kairuz, ante el "aspecto de soledad y estancamiento”, propuso esa estación como terminal de ómnibus (La Nueva Provincia, 20/9/1965).

Con un día de diferencia se publicaron en La Nueva Provincia dos crónicas que testimonian las pugnas desatadas entre ambos barrios, quedando al descubierto sus entidades antagónicas:

Organizada por comerciantes, industriales, entidades y vecinos del barrio Noroeste, se llevó a cabo anoche una asamblea vecinal en el fogón del club Almafuerte... En su transcurso fue elegida la Junta Vecinal Pro-Estación Terminal de Ómnibus Bahía Blanca Noroeste, que tendrá a su cargo la realización de un movimiento tendiente a interesar a la opinión pública y fuerzas vivas de nuestra ciudad en apoyo del proyecto del diputado provincial de la UCRI, señor Juan Kairuz. La iniciativa del legislador propicia la utilización de los terrenos que el Ferrocarril ocupa sobre la calle Sixto Laspiur. Asimismo, las instalaciones permitirán el normal movimiento en la Estación Noroeste (La Nueva Provincia, 4/2/1966).

La Comisión pro Terminal de Ómnibus en la exestación Rosario —organismo que integran varias entidades de Villa Mitre, Tiro Federal, Barrio Anchorena y Villa Loreto- continúa realizando gestiones en el cumplimiento de su objetivo, a cuyo efecto acaba de dirigir un memorial a la presidencia de la Cámara de Diputados de la Provincia de Buenos Aires. Al mismo tiempo, copias 
5. "La Junta Vecinal Pro Terminal de Ómnibus en la Estación Ferroviaria Bahía Blanca Noroeste, con motivo de expresiones formuladas durante la audición 'Debate

9', difundida en la noche del último viernes por

Telenueva y LU2 Radio Bahía Blanca, ha dado a conocer una declaración dirigida a la opinión pública. Concretamente se refiere

a algunas manifestaciones del diputado provincial José Glasman y del ex comisionado y ex concejal doctor Alejandro Pérez".

"Una Declaración. Terminal de Ómnibus para Bahía

Blanca”. La Nueva Provincia, 28 de febrero de 1966.

"Con la firma de los señores Ginés García y Jorge Chaime - presidente y secretario de la entidad, respectivamente-

la Comisión Pro Terminal de Ómnibus en la exestación Rosario ha dado a conocer el texto de una resolución adoptada por el organismo de referencia". "Terminal de Ómnibus. Apoyo para la ex Estación Rosario".

La Nueva Provincia, 6 de marzo de 1966. de dicho documento -en el que se puntualizan detalles que avalan la posición del organismo de referencia- han sido despachadas a todos los bloques que constituyen la mencionada Cámara legislativa provincial (La Nueva Provincia, 3/2/1966)

Entre febrero y marzo de 1965 continuaron las impugnaciones entre ambos promotores. ${ }^{5}$ Aparentemente, el diputado Kairuzal al plantear que la terminal ocupara la estación del ex FCBBNO encontraba resistencia en la Unión Ferroviaria, interesada en su conservación junto a los talleres aledaños, "los talleres invisibles", como los llamó Miravalles (2013). Aquella junta pretendía la reactivación de Almafuerte, para mitigar el estancamiento barrial, brindar comodidad a los vecinos, impedir yuyales y marginalidad que la opción de la terminal disiparía. El otro bando, aliado de la Unión Ferroviaria y tutelando objetivos del sector sureste, veía en la estación del ex FCRPB un edificio ferroviario desafectado y ningún motivo para suponer que una nueva sede de transportes evitaría los baldíos mencionados. La controversia finalizó a favor de la segunda opción, que permite comprender los ribetes de esa cultura urbana como campo de lucha y resistencia entre sectores subalternos (Altamirano, 2002). Ello, en parte, explica la tardía resolución del conflicto en 1979, cuando fue inaugurada la terminal de ómnibus provisoria en la estación Rosario.

\section{Reestructuración ferro-urbanística para el desarrollo regional según el plan director}

Quienes prosiguieron abordando la ciudad como sistema integral fueron los urbanistas, pero ya no lo harían guiados por la metáfora del organismo vivo. Drásticos cambios en los cuerpos docentes universitarios incluirían nuevas perspectivas académicas tras la "Revolución Libertadora”. Ello

Suponía una profesión de fe respecto a los lineamientos del planning anglosajón, en este caso específicamente el norteamericano, en contraposición a la noción de urbanismo claramente revelador de los lazos de la primera invención de la disciplina con la escuela francesa (RigotTi, 2014, p. 97).

Ese paradigma estaba atravesado por la noción de planificación que emanaba de la burocracia estatal inspirada en la Teoría de la Modernización. Esa doctrina introdujo una expectativa de crecimiento para los países en "vías de desarrollo" y hermanó a Latinoamérica en organismos panamericanos de cooperación. También condujo al Estado provincial a incidir 
sobre el desarrollo urbano con una mirada tecnocrática que reemplazaba la encomienda profesional por el equipo técnico municipal.

La complejidad temática hizo incorporar a la región, y el planeamiento dio origen al Plan Director: un conjunto de disposiciones que operaban como instrumento jurídico. Asimismo, los vaivenes en las ideas políticas fueron asumidos e incorporados por los urbanistas. De ese modo, asociaron los planes de gobierno a las novedades disciplinares traídas desde Inglaterra, Francia y Estados Unidos. ${ }^{6}$ En ese contexto exploratorio del Urbanismo en la Argentina, fueron institucionalizados los criterios de planeamiento que eran impulsados por el arquitecto José Pastor al introducir la escala regional (MAzzA, 2004). Imbuida en esos novedosos alcances, en 1959 la Municipalidad de Bahía Blanca solicitó colaboración a la Organización de los Estados Americanos (OEA). Esta envió la Misión 40 para auxiliar al Municipio en su promoción económica. De ello resultó un informe con los lineamientos de un futuro plan regional. ${ }^{7}$ El plan fue el germen de la Dirección de Planeamiento y Vivienda (1967), orientada a realizar el Plan de Desarrollo publicado en 1971 y reformulado en 1986 (AA. VV., 1971).

El equipo hizo estimaciones, proyecciones y proposiciones que evidencian una nueva "invención” del Urbanismo, interpelada por otro contexto histórico, epistemológico y disciplinar. Los problemas ferroviarios reaparecieron: "La ciudad no puede seguir surcada por una excesiva cantidad de líneas férreas que, como se ha mostrado, tuvieron su origen en intereses de las empresas ferroviarias” (AA. VV., 1971, pág. 124). Por ello, la Reestructuración Ferroviaria proponía mantener la ubicación de la estación de pasajeros (ex FCS); reducir los perjuicios que su ramal de acceso N-S traía a la trama urbana; suprimir las playas y enlaces del ex FCBBNO y construir una nueva estación de cargas junto al área industrial. La nueva terminal de ómnibus de larga y media distancia sería construida en un terreno que se iba a expropiar, delimitado por las calles San Luis, Chiclana y vías del ferrocarril, cercano a la exestación Sud.

La prensa recogió con beneplácito los visos preliminares del plan aludiendo a un problema pendiente y a los consabidos parangones: "Rosario y Comodoro Rivadavia fueron favorecidas ya por la decisión de transformar la incidencia del ferrocarril dentro del desarrollo urbano. Bahía Blanca sigue en turno" (LA Nueva Provincia, 9/6/1968) Cabe aclarar que meses antes el interventor de Ferrocarriles Argentinos había declarado con crudeza:
6. Una gran sala de ensayos fue la reconstrucción de la ciudad de San Juan tras el terremoto del año 1944.

7. Algunas conclusiones fueron: "la necesidad de creación de una organización regional para el desarrollo del área mediante una Junta Regional de Intendentes, la definición de una Comisión de Desarrollo Urbano de Bahía Blanca y la creación de una Oficina Técnica del Plan de Desarrollo" (p. 13). 

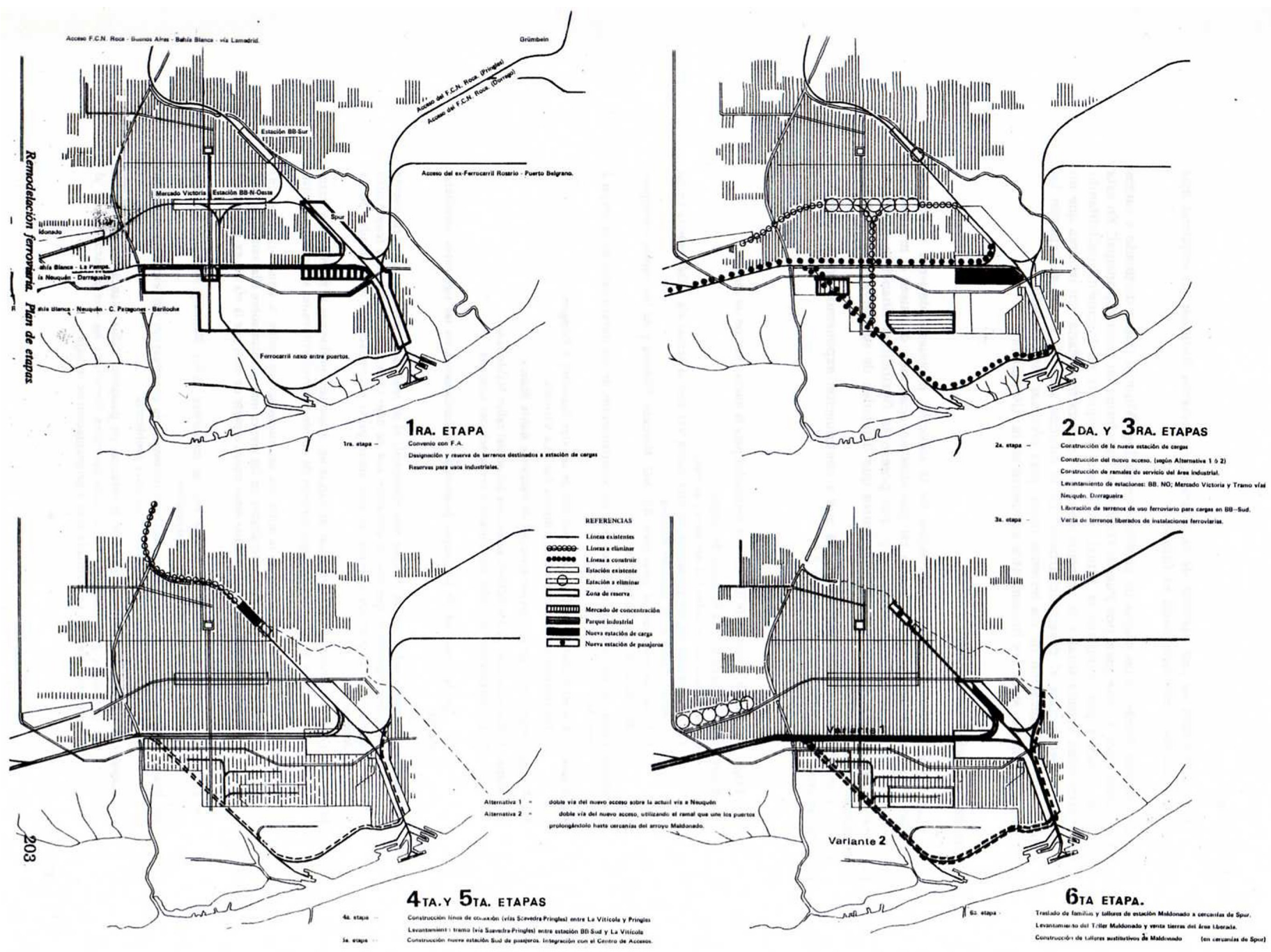

Figura 7. Reestructuración Ferroviaria. Plan de etapas. (Circunferencias: elementos que eliminar. Círculos y líneas negras: elementos que construir). Fuente: Plan de Desarrollo de Bahía Blanca (1971) Dirección General de Planeamiento y Vivienda, Municipalidad de Bahía Blanca, pág. 203 
Es verdad que en muchos lugares el ferrocarril frena el crecimiento de las ciudades. Eso ocurre en Rosario, donde estamos trabajando para poner las cosas en su lugar. Pero no lo haremos en ningún otro lugar, Bahía Blanca incluido, porque hay otras cosas más apremiantes (LA NuEva Provincia, 14/1/1968).

Cuando el plan fue publicado (La Nueva Provincia, 8/7/1969), se creó una comisión entre Ferrocarriles Argentinos, el Ministerio de Obras Públicas de la Provincia y la Municipalidad de Bahía Blanca, pero no hubo acuerdo (figura 7) (LA Nueva Provincia, 2/4/1972).

En 1986 el Departamento Planeamiento Urbano realizó la Reformulación del Plan de Desarrollo Urbano, que fue publicada como Plan Director. Haciendo mención al zanjado emplazamiento de la terminal, el documento versa: "La actual ubicación de la terminal de colectivos de media y larga distancia es un interesante ejemplo de refuncionalización urbana... supo aprovecharse una estación ferroviaria desactivada que cumple con prácticamente todos los supuestos que se establecían” (AA. VV., 1986, pág. 240). Asimismo, el Plan Director sugería una superficie de ampliación para estacionamiento de colectivos, donde luego fue construido el edificio definitivo en el año 2008.

\section{Epílogo}

Las oscilaciones manifiestas alrededor de la ubicación de la terminal de ómnibus de Bahía Blanca exponen una serie de conflictos y pugnas entre representaciones sociales, condiciones locales, medidas estatales y saberes técnicos en torno a la infraestructura ferroviaria. No obstante, en relación con la imposibilidad de ejecutar las propuestas urbanísticas, es necesario recordar que en pocas ciudades argentinas los planes urbanos llegaron a buen puerto. Si bien los municipios dispusieron de ellos para legitimar "científicamente" sus demandas, en Bahía Blanca las concreciones locales estuvieron más próximas a prácticas puntuales definidas por la sociedad civil como prioritarias. Ese pragmatismo abrió una brecha entre lo imaginado y lo realizado. Asimismo, en ciudades argentinas consideradas objetivos estratégicos del Ministerio de Transporte de la Nación (como Rosario o Buenos Aires), algunos planes hallaron mayor respaldo estatal, lo que demuestra algunas concreciones. Así, los vaivenes en torno al emplazamiento de la terminal bahiense y su ubicación en la ex estación FCRPB prueban el fracaso de quienes proponían una ciudad nueva desde las aspiraciones de la técnica y la política, al tiempo que reflejan las disputas entre aquellos sectores sociales que, con total pragmatismo, aportaban a la renovación urbana en acciones puntuales. 


\section{Referencias bibliográficas}

AA. VV. (1971). Plan de Desarrollo de Bahía Blanca. Dirección General de Planeamiento y Vivienda, Municipalidad de Bahía Blanca.

AA. VV. (1986). Reformulación del Plan de Desarrollo Urbano de Bahía Blanca. Secretaría de Obras y Servicios, Municipalidad de Bahía Blanca.

ALTAMIRANO, Carlos (Dir.) (2002) Términos críticos de sociología de la cultura. Buenos Aires: Paidós.

CERNADAS de BULNES, Mabel (1996). Bahía Blanca de Ayer y Hoy. En Segundo seminario sobre historia y realidad bahiense, UNS, Bahía Blanca.

GUERREIRO, Héctor (2011). Los ferrocarriles en Bahía Blanca. Tomo 1 y 2. Bahía Blanca: Fondo Municipal de las Artes y Ferrowhite.

LÓPEZ, Mario Justo (2008). El problema ferroviario argentino y la nacionalización de las compañías de capital británico en 1948. TST. Revista de Historia. Transporte, Servicios y Telecomunicaciones, N. ${ }^{\circ}$ 15, pp. 113-145.

MAZZA, Carlos (2004). A historical approach to the study of town and regional plans originated in regional planning in Argentina, 1940-1960. The 11th International Planning History Conference, Barcelona. Recuperado de: http://www.etsav. upc.es/personals/iphs2004/pdf/129_p.pdf

MIRAVALLES, Ana (2013). Los talleres invisibles: una historia de los talleres ferroviarios Bahía Blanca Noroeste. Bahía Blanca: Ferrowhite.

RIBAS, Diana (2007). Del fuerte a la ciudad moderna: imagen y autoimagen de Bahía Blanca. Tesis Doctorado en Historia (inédita), Universidad Nacional del Sur, Bahía Blanca.

RIGOTTI, Ana María (2014). Las invenciones del Urbanismo en Argentina (1900-1960). Inestabilidad de sus representaciones científicas y dificultades para su profesionalización. Rosario: UNR Editora. Recuperado de: http://hdl.handle. net/2133/3567

ROCA, Miguel C. (1950). Plan Regulador de Bahía Blanca. Revista de Arquitectura, N. ${ }^{\circ}$ 359, año XXXV, pp. 329-332.

ROCA, Miguel C. (1950). Remodelación ferroviaria y urbanística de la ciudad de Bahía Blanca. Revista de Arquitectura, N. $^{\circ}$ 359, año XXXV, pp. 320-328.

SCALABRINI ORTIZ, Raúl [1940] (2006). Historia de los Ferrocarriles Argentinos. Buenos Aires: Lancelot. 
SCHUSTER, Federico. (Comp). (2002). Filosofía y métodos de las ciencias sociales. Buenos Aires: Manantial.

WADDELL, Jorge (2009). De la nacionalización a la privatización de Menem. Ferrocarriles Argentinos: 60 años de decadencia. En LUNA, Félix, Esplendor y ocaso de los ferrocarriles, Revista Todo es Historia, Buenos Aires, N. ${ }^{\circ}$ 509. pp. 58-77.

\section{Fuentes}

Archivo del Museo Taller Ferrowhite.

Archivo Histórico Municipal de Bahía Blanca.

Hemeroteca y Mapoteca de la Asociación Bernardino Rivadavia - Biblioteca Popular.

Municipalidad de la Ciudad de Bahía Blanca.

\section{Documentos periodísticos}

\section{Diario Bahía Blanca}

“Aquel fantástico plano”, Bahía Blanca, año IV, N. ${ }^{\circ}$ 1107, domingo 28 de noviembre de 1909, p. 1.

"Bouvard, ingeniero, en La Plata. Dujarric, arquitecto, en B. Blanca”, Bahía Blanca, año IV,

\section{Diario El Atlántico}

$$
\text { N. }{ }^{\circ} 1042 \text {, sábado } 11 \text { de septiembre de 1909, p. } 4 .
$$

“Como terminal de ómnibus podría habilitarse la ex-estación R. P. B”. El Atlántico, 18 de marzo de 1952.

\section{Diario El Censor}

"Manía de grandezas. Bahía Blanca y su ensanche futuro", El Censor, Bahía Blanca, año III,

\section{Diario La Nación}

$$
\text { N. }{ }^{\circ} 251 \text {, miércoles } 24 \text { de noviembre de 1909, p. } 1 .
$$

LUGONES, Benigno (1883) “Una excusión al Sur, la vida en Bahía Blanca”, La Nación, Buenos Aires, año 14, N. ${ }^{\circ}$ 3754, p. 1.

\section{Diario La Nueva Provincia}

"Bahía Blanca en el futuro. Plan de transformación urbana”, La Nueva Provincia, Bahía Blanca, año XII, N. ${ }^{\circ} 3283$, martes 23 de noviembre de 1909, p. 2.

"El nuevo plano de B. Blanca. Descripción del proyecto", La Nueva Provincia, Bahía Blanca, año XII, N. ${ }^{\circ} 3285$, jueves 25 de noviembre de 1909, p. 2.

"Desaparecerán Tres de las Estaciones Existentes, con el Proyectado Plan de Reordenamiento Ferroviario”. La Nueva Provincia. 10 de junio de 1949. 
“Una vieja estación debe ser mejorada o bien desaparecer”. La Nueva Provincia, 14 de febrero de 1949.

"La Remodelación Ferroviaria de Bahía Blanca y la Próxima Visita a Esta del Ministro de Trasportes” (sic). La Nueva Provincia, 28 de mayo de 1949.

"Desde ayer es huésped en nuestra ciudad el Ministro de Trasportes” (sic). La Nueva Provincia, 2 de junio de 1949.

“Gestiona la Municipalidad la Cesión de las instalaciones de la Ex Estación Rosario”. La Nueva Provincia, 10 de junio de 1958.

"Los Problemas de Bahía Blanca. Aeropuerto-Terminal de Ómnibus-Estaciones-Accesos-Transportes”. La Nueva Provincia, 14 de marzo de 1962.

“Ex Estación Rosario. La habilitarán como terminal de ómnibus”. La Nueva Provincia, 26 de diciembre de 1962.

“Visita a la Ex Estación Rosario. Gestiónase la Instalación de la Terminal de Omnibus”. La Nueva Provincia, 29 de diciembre de 1962.

“En el Barrio Almafuerte. Piden la Rehabilitación de la Estación Bahía Blanca N. O.” La Nueva Provincia, 29 de mayo de 1962.

"Pídese la Rehabilitación de la Estación Bahía Blanca Noroeste”. La Nueva Provincia, 8 de octubre de 1964.

“Llamada a mejor destino”. La Nueva Provincia, 20 de septiembre de 1965.

“Adhesión a un Proyecto. Terminal de Ómnibus en la Estación Noroeste”. La Nueva Provincia, 4 de febrero de 1966.

“Terminal de ómnibus en la exestación Rosario”. La Nueva Provincia, 3 de febrero de 1966. "El Ferrocarril ante el Progreso de la Ciudad”. La Nueva Provincia, 9 de junio de 1968.

“Romper el ‘Cinturón de Hierro’. El Ejemplo de Rosario”. La Nueva Provincia, 14 de enero de 1968.

“La Elaboración del Plan Regulador para Bahía Blanca”. La Nueva Provincia, 8 de julio de 1969.

"Debe superarse la Etapa de Indefinición. Remodelación Ferroviaria: Plan que Requiere Consideración Formal”. La Nueva Provincia, 2 de abril de 1972. 